\title{
In aged people, should we stick to normal range?
}

\begin{abstract}
Introduction: Pulmonary hypertension is a substantial global health issue. All age groups are affected with rapidly growing importance in elderly people, particularly in countries with ageing populations.

Aim of the study was to evaluate the effect of aging on resting pulmonary artery systolic pressure non-invasively using TTE.

Patients and methods: We recruited 200 elderly patients referred for echocardiographic evaluation at Heliopolis and Ain Shams University Hospitals in the period from August 2017 to February 2018 and assessed them echocardiographically for PAP.

Results: our data showed that $47 \%$ of patients had PASP $>35 \mathrm{mmHg}$ and $24 \%$ had PASP $>40 \mathrm{mmHg}$. Systemic hypertension was prevalent among patients with abnormal PASP. Most of patients had grade I diastolic dysfunction $(92 \%)$ that showed a non -significant correlation with pulmonary artery pressure. Only $3 \%$ of patients had severe form of dysfunction. There was a highly significant positive correlation between age and PASP.

Conclusion: Pulmonary artery systolic pressure was higher than the expected normal values $(35 \mathrm{mmHg})$ in $47 \%$ of patients above 60 years of age and this dropped to $24 \%$ when $40 \mathrm{mmHg}$ was used as the cutoff value for normal level. No gender predilection of abnormal PASP in the aged population. Systemic hypertension was prevalent among patients with abnormal PASP. Pulmonary artery systolic pressure showed a significant direct correlation with age.
\end{abstract}

Keywords: pulmonary hypertension, aging, pulmonary artery pressure, TAPSE, PAT, echocardiography, aging, pulmonary artery pressure, TAPSE, PAT, echocardiography
Volume I2 Issue I - 2019

\author{
Adham Abdeltawab, Mohamed Shehata, \\ Ahmed Samy, Mona Rayan \\ Cardiology department, Ain Shams University, Egypt
}

Correspondence: Adham Abdeltawab, Cardiology department, Ain Shams University, Cairo, Egypt, Tel +20I008800788, Email adham_abdeltawab@med.asu.edu.eg, adham Ist@yahoo. com

Received: January 31, 2019 | Published: February 22, 2019
Abbreviations: $\mathrm{PH}$, pulmonary hypertension; PAP, pulmonary artery pressure; RA, right atrial; RV, right ventricle; RVSP, right ventricular systolic pressure; LV, left ventricle; EDD, end diastolic diameter; ESD, end systolic diameter; MPAP, mean pulmonary artery pressure; AT, acceleration time; IHD, ischemic heart disease; TR, tricuspid regurgitation; DD, diastolic dysfunction; MR, mitral regurgitation; EF, ejection fraction; PAT, pulmonary acceleration time

\section{Introduction}

Pulmonary hypertension in elderly gained a lot of interest recently. Over the previous two decades, there is an increase in the diagnosis of PH in hospitalized patients aged 65 and over. Due to the nonspecific symptoms and signs, especially early in the disease, clinical suspicion is necessary in detecting the disease before irreversible pathophysiologic changes occur. In this regard, transthoracic echocardiography, by providing direct and/or indirect signs of elevated pulmonary artery pressure (PAP), is an excellent noninvasive screening test for patients with symptoms or risk factors for PH. It may also provide important information on both the etiology and the prognosis. ${ }^{1}$

\section{Aim of the study}

The aim of this study was to evaluate the effect of aging on resting pulmonary artery systolic pressure non-invasively.

\section{Patients and methods}

This study is a Cross sectional observational study which was conducted on 200 patients, at least 60 years old, referred for echocardiographic evaluation at Heliopolis and Ain Shams university Hospitals in the period from August 2017 to February 2018.
Exclusion criteria: Patients who had one or more of the following were excluded from the study:

1. Causes of secondary pulmonary hypertension as:-

2. Significant valvular heart disease (defined by more than mild stenosis and/or regurgitation of any cardiac valve or previous valve repair or replacement).

3. Severe Left ventricular systolic dysfunction (resting LV ejection fraction $<35 \%$ ).

4. Known congenital heart disease.

5. Known cases of significant lung condition diagnosed by CT chest.

6. Known cases of 1ry pulmonary hypertension.

All patients were subjected to the following:

1. Thorough history taking that included age, gender, risk factors of medical importance and history of chest or cardiac disease.

2. Local cardiac examination to exclude significant valvular affection.

\section{Echocardiographic assessment}

AllpatientsunderwentStandard transthoracic2Dechocardiographic examination with machine-integrated ECG recording was performed, mostly with the patients lying in the left lateral decubitus position, using GE machine vivid 5 with an M3S matrix sector array probe with a frequency of $2.5 \mathrm{Mega} \mathrm{Hz}$. the standard views were done according to the recommendations of American society of Echocardiography. ${ }^{2}$

All patients underwent the following measurements 
1. Left ventricular study including diameters and volumes (EDD and volume, ESD and volume) and ejection fraction using 2D planimetry. Assessment of LV diastolic function using mitral inflow at the mitral valve tip using pulsed Doppler waves in the apical 4 chamber view. Assessment of segmental wall motion to exclude the presence of abnormality.

2. The anteroposterior diameter of the left atrium was measured in the parasternal long-axis view using M-mode perpendicular to the aortic root long axis at the level of the aortic sinuses by using the leading-edge to leading-edge.

3. Right side assessment including right ventricular basal, mid and longitudinal diameter, TAPSE measurement, pulmonary artery systolic pressure using the following formula ( $\mathrm{RVSP}=4(\mathrm{~V})^{2}+\mathrm{RA}$ pressure) where $\mathrm{V}$ is the peak velocity (in meters per second) of the tricuspid valve regurgitant jet and RA pressure is estimated from IVC diameter and respiratory changes.

Mean pulmonary artery pressure using the following formulas: Mean PA pressure $=79(0.45 \times \mathrm{AT})$ and if $\mathrm{ATs}<120 \mathrm{~ms}$, the formula for mean PA pressure is $90(0.62 \times A T)$. The acceleration time (AT) was measured using PW Doppler on pulmonary valve in short axis aortic level. ${ }^{3}$ If pulmonary regurgitation was detected, the following formula was used $\mathrm{PADP}=4 \mathrm{x}$ (end-diastolic pulmonary regurgitant velocity $)^{2}+\mathrm{RAP}$ and mean PA pressure $=1 / 3(\mathrm{SPAP})+2 / 3(\mathrm{PADP}){ }^{4}$

\section{Results}

The mean age was $64.5 \pm 5.90$, with no gender predominance $(51 \%)$ was males and $(49 \%)$ were females. Hypertension existed in $63 \%$ of patients, DM in $40 \%$ of patients, $22 \%$ was active smokers and $5 \%$ were exsmokers, $24 \%$ of patients had history of IHD. Normal left ventricular dimensions and preserved systolic function with a mean EF of $61.09 \pm 5.75 \%$ were found in the study group. $80.5 \%$ of patients had DD grade 1,87.5\% of the patients had MR of an area less than 4 $\mathrm{cm} 2$ in any view associated with mitral valve degeneration. Right side study revealed the presence of mild TR in $97.5 \%$ of study population, with mean TR velocity $2.52 \mathrm{~ms}$, mean PAT $93.9 \mathrm{~ms}$ and mean MPAP $32.5 \mathrm{mmHg}$. And mean RVSP $35.7 \mathrm{mmHg}$. The details are shown in Table 1. Defining $35 \mathrm{mmHg}$ as the cut off value for normal level of RVSP and PASP, the incidence of abnormal RVSP was $47 \%$. This prevalence dropped to $24 \%$ ( 47 patients) when $40 \mathrm{mmHg}$ was used as a cut off point for defining normal RSVP level.

Table I Echocardiographic data of the right side study

\begin{tabular}{lll}
\hline Variables & & No. $=\mathbf{2 0 0}$ \\
\hline RV Basal diameter & Mean \pm SD & $3.28 \pm 0.42$ \\
RV Mid diameter & Mean \pm SD & $2.91 \pm 0.55$ \\
RV Apical diameter & Mean \pm SD & $4.51 \pm 0.53$ \\
TAPSE & Mean \pm SD & $2.04 \pm 0.25$ \\
TR & Mild & $195(97.5 \%)$ \\
TR velocity & Moderate & $5(2.5 \%)$ \\
PAT & Mean \pm SD & $2.52 \pm 0.31$ \\
MPAP & Mean \pm SD & $93.95 \pm 16.24$ \\
RVSP & Mean $\pm S D$ & $32.50 \pm 8.36$ \\
\hline
\end{tabular}

Based on the defined cut off value, we divided our cohort of patients into two subgroups: patients with RVSP $>35 \mathrm{mmHg}$ and patients with RVSP $\leq 35 \mathrm{mmHg}$. Both groups were comparable as regards demographic data and risk factors distribution. These data are shown in Table 2. The echocardiographic data of the left side were comparable in the two groups with higher incidence of diastolic dysfunction grade II, III in patients with abnormal RVSP that didn't reach statistical significance. The details of these data are shown in Table 3. On the other hand, the echocardiographic evaluation of the right side showed significant increase in the severity of the tricuspid regurge in patients with abnormal RVSP. The data are shown in Table 4. Aging showed a highly significant positive correlation with MPAP, RVSP, TR velocity and a highly significant negative correlation with TAPSE and PAT. These data are shown in Table 5, (Figure 1-3). Univariate linear regression analysis for factors affected by age in the study group showed that age affected significantly tricuspid velocity, pulmonary acceleration time, mean pulmonary artery pressure and RVSP as shown in Table 6. Multi-regression analysis shows that age is an independent predictor of increased RVSP yet not MPAP as shown in Table 7.

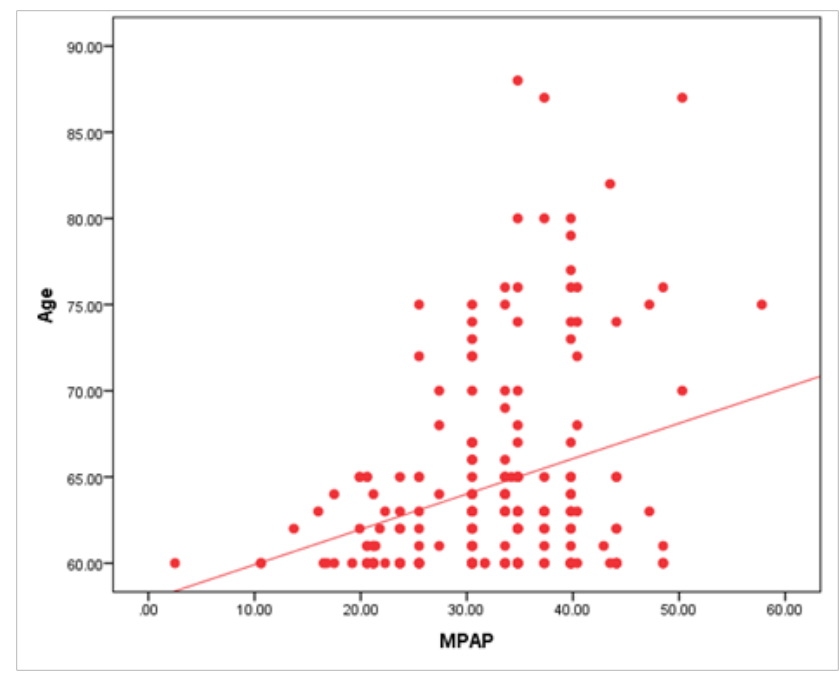

Figure I Positive correlation between age and MPAP.

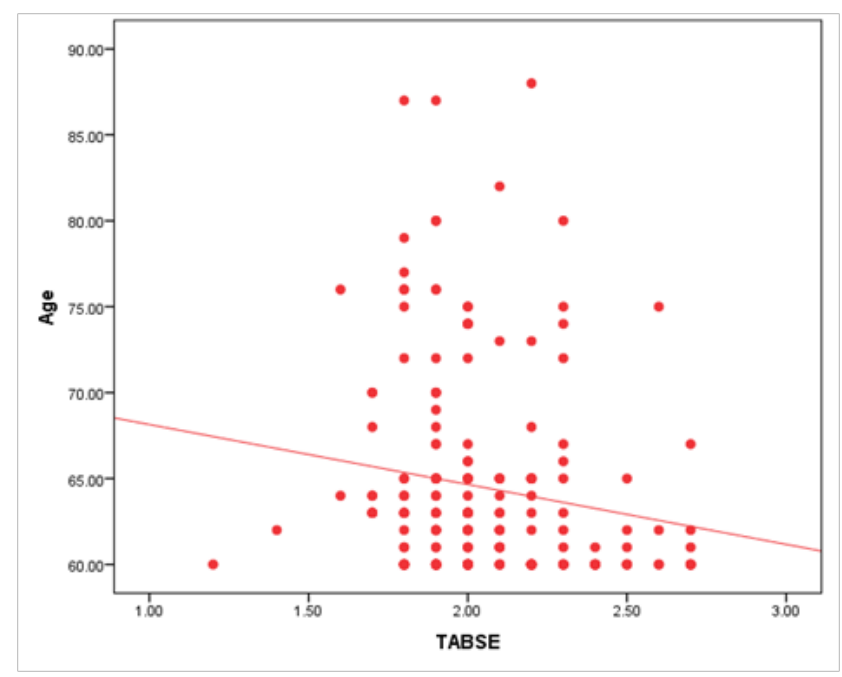

Figure 2 Negative correlations between age and TAPSE. 
Table 2 Compares demographic data of patients with normal and abnormal pulmonary artery pressure

\begin{tabular}{|c|c|c|c|c|c|c|}
\hline \multirow{2}{*}{ History } & & \multirow{2}{*}{$\begin{array}{l}\text { RVSP } \leq 35 \\
\text { No. }=106(53 \%)\end{array}$} & \multirow{2}{*}{$\begin{array}{l}\text { RVSP }>35 \\
\text { No. }=94(47 \%)\end{array}$} & \multirow{2}{*}{ Test value } & \multirow{2}{*}{ P-value } & \multirow{2}{*}{ Sig. } \\
\hline & & & & & & \\
\hline Age & Mean \pm SD & $64.00 \pm 5.06$ & $65.07 \pm 6.71$ & -1.287 & 0.2 & NS \\
\hline \multirow{2}{*}{ Gender } & Female & $47(44.3 \%)$ & $51(54.3 \%)$ & 1.96 & 0.161 & NS \\
\hline & Male & $59(55.7 \%)$ & $43(45.7 \%)$ & & & \\
\hline DM & Positive & $41(38.7 \%)$ & $38(40.4 \%)$ & 0.064 & 0.801 & NS \\
\hline \multirow[t]{2}{*}{ HTN } & Positive & $65(61.3 \%)$ & $61(64.9 \%)$ & 0.273 & 0.601 & NS \\
\hline & Negative & $77(72.6 \%)$ & $70(74.5 \%)$ & & & \\
\hline \multirow[t]{2}{*}{ Smoker } & Positive & $24(22.6 \%)$ & $20(21.3 \%)$ & 0.088 & 0.957 & NS \\
\hline & EX smoker & $5(4.7 \%)$ & $4(4.3 \%)$ & & & \\
\hline IHD & Positive & $27(25.5 \%)$ & $20(21.3 \%)$ & 0.488 & 0.485 & NS \\
\hline
\end{tabular}

Table 3 Compares echocardiographic data of the left side in patients with normal and abnormal pulmonary artery pressure

\begin{tabular}{|c|c|c|c|c|c|c|}
\hline \multirow{2}{*}{ Variables } & & RVSP $\leq 35$ & RVSP $>35$ & \multirow{2}{*}{ Test value } & \multirow{2}{*}{ P-value } & \multirow{2}{*}{ Sig. } \\
\hline & & No. $=106$ & No. $=94$ & & & \\
\hline LVEDD & Mean \pm SD & $4.98 \pm 0.51$ & $5.04 \pm 0.56$ & -0.704 & 0.482 & NS \\
\hline LVESD & Mean \pm SD & $3.35 \pm 0.45$ & $3.36 \pm 0.48$ & -0.072 & 0.942 & NS \\
\hline IVSD & Mean \pm SD & $0.98 \pm 0.23$ & $1.00 \pm 0.26$ & -0.572 & 0.568 & NS \\
\hline LVPWD & Mean \pm SD & $1.10 \pm 1.19$ & $1.02 \pm 0.21$ & 0.619 & 0.537 & NS \\
\hline EF & Mean \pm SD & $60.75+5.31$ & $61.48 \pm 6.20$ & -0.901 & 0.369 & NS \\
\hline FS & Mean \pm SD & $33.22 \pm 6.75$ & $33.20 \pm 3.98$ & 0.019 & 0.985 & NS \\
\hline LA & Mean \pm SD & $4.33 \pm 0.40$ & $4.41 \pm 0.40$ & -1.504 & 0.134 & NS \\
\hline $\mathrm{AO}$ & Mean \pm SD & $3.00 \pm 0.32$ & $3.11 \pm 0.35$ & -2.155 & 0.032 & $\mathrm{~S}$ \\
\hline \multirow{4}{*}{ DD } & None & $5(4.7 \%)$ & $3(3.2 \%)$ & \multirow{4}{*}{2.09} & \multirow{4}{*}{0.554} & \multirow{4}{*}{ NS } \\
\hline & I & $88(83.0 \%)$ & $73(77.7 \%)$ & & & \\
\hline & II & $12(11.3 \%)$ & $16(17.0 \%)$ & & & \\
\hline & III & $1(0.9 \%)$ & $2(2.1 \%)$ & & & \\
\hline \multirow{4}{*}{ MR } & None & $5(4.7 \%)$ & $1(1.1 \%)$ & \multirow{4}{*}{3.123} & \multirow{4}{*}{0.21} & \multirow{4}{*}{ NS } \\
\hline & I & $0(0.0 \%)$ & $0(0.0 \%)$ & & & \\
\hline & II & $93(87.7 \%)$ & $82(87.2 \%)$ & & & \\
\hline & III & $8(7.5 \%)$ & $11(11.7 \%)$ & & & \\
\hline
\end{tabular}

Table 4 compares echocardiographic data of the right side in patients with normal and abnormal pulmonary artery pressure

\begin{tabular}{|c|c|c|c|c|c|c|}
\hline \multirow{2}{*}{ Variables } & & $\mathrm{RVSP} \leq 35$ & RVSP > 35 & \multirow{2}{*}{ Test value } & \multirow{2}{*}{ P-value } & \multirow{2}{*}{ Sig. } \\
\hline & & No. $=106$ & No. $=94$ & & & \\
\hline RV Basal & Mean \pm SD & $3.26 \pm 0.43$ & $3.30 \pm 0.42$ & -0.8 & 0.425 & NS \\
\hline RV Mid & Mean \pm SD & $2.85 \pm 0.55$ & $2.97 \pm 0.55$ & -1.582 & 0.115 & NS \\
\hline RV Apical & Mean \pm SD & $4.46 \pm 0.48$ & $4.56 \pm 0.59$ & -1.245 & 0.215 & NS \\
\hline TABSE & Mean \pm SD & $2.03 \pm 0.24$ & $2.06 \pm 0.27$ & -0.839 & 0.403 & NS \\
\hline \multirow{2}{*}{$\mathrm{TR}$} & Mild & $106(100.0 \%)$ & $89(94.7 \%)$ & \multirow{2}{*}{5.783} & \multirow{2}{*}{0.016} & \multirow{2}{*}{$\mathrm{S}$} \\
\hline & Moderate & $0(0.0 \%)$ & $5(5.3 \%)$ & & & \\
\hline TR velocity & Mean \pm SD & $2.31 \pm 0.22$ & $2.76 \pm 0.21$ & -15.02 & 0 & HS \\
\hline PAT & Mean \pm SD & $95.16 \pm 15.91$ & $92.59 \pm 16.59$ & 1.12 & 0.264 & NS \\
\hline MPAP & Mean \pm SD & $31.78 \pm 8.22$ & $33.35 \pm 8.47$ & -1.335 & 0.183 & NS \\
\hline
\end{tabular}




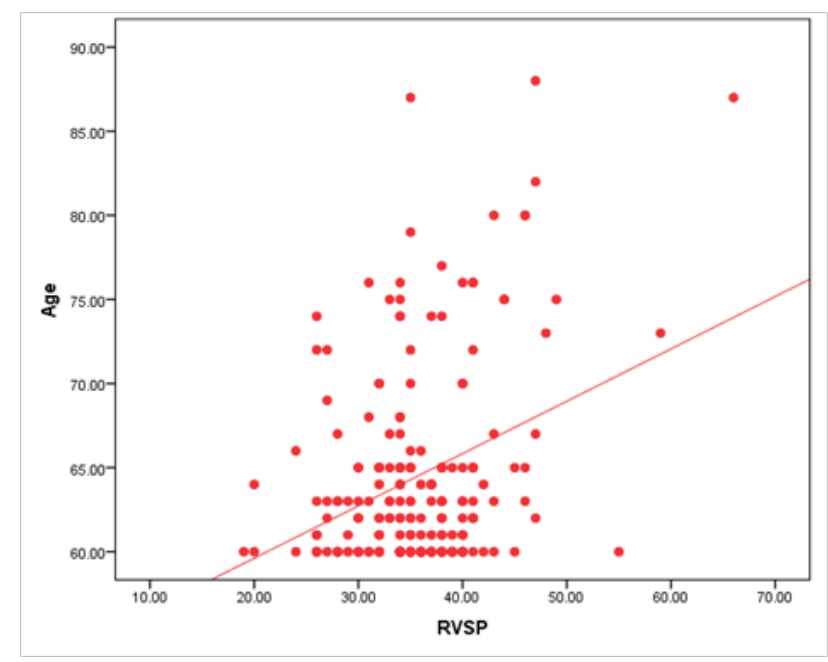

Figure 3 Positive correlation between age and RVSP.

Table 5 Shows the Correlation between age and right-side parameters

\begin{tabular}{lll}
\hline \multirow{2}{*}{ Variables } & \multicolumn{2}{l}{ Age } \\
\cline { 2 - 3 } & $\mathbf{R}$ & P-value \\
\hline RV Basal diameter & 0.091 & 0.2 \\
RV Mid diameter & -0.046 & 0.518 \\
RV Apical diameter & -0.029 & 0.681 \\
TAPSE & $-0.195 * *$ & 0.006 \\
TR velocity & $0.159 *$ & 0.024 \\
PAT & $-0.223 * *$ & 0.002 \\
MPAP & $0.223 * *$ & 0.001 \\
RVSP & $0.164 *$ & 0.02
\end{tabular}

Table 6 Univariate linear regression analysis for factors affected by aging

\begin{tabular}{llllll}
\hline & \multicolumn{2}{l}{$\begin{array}{l}\text { Unstandardized } \\
\text { coefficients }\end{array}$} & $\begin{array}{l}\text { Standardized } \\
\text { coefficients }\end{array}$ & T & Sig. \\
\cline { 2 - 4 } & $\mathbf{B}$ & $\begin{array}{l}\text { Std. } \\
\text { error }\end{array}$ & Beta & & \\
\cline { 1 - 3 } (Constant) & 60.517 & 1.717 & & 35.239 & 0 \\
IVSD & 4.026 & 1.683 & 0.168 & 2.392 & 0.018 \\
LVPWD & 0.6 & 0.477 & 0.089 & 1.258 & 0.21 \\
FS & -0.08 & 0.075 & -0.076 & -1.067 & 0.287 \\
TAPSE & -0.3 & 0.307 & -0.069 & -0.977 & 0.33 \\
TR velocity & 5.836 & 1.298 & 0.304 & 4.495 & 0 \\
PAT & -0.105 & 0.025 & -0.29 & -4.268 & 0 \\
MPAP & 0.205 & 0.047 & 0.299 & 4.408 & 0 \\
RVSP & 0.311 & 0.063 & 0.33 & 4.912 & 0 \\
\hline
\end{tabular}

\section{Discussion}

Pulmonary hypertension is a hemodynamic and pathophysiological condition defined as increase in mean pulmonary arterial pressure $\geq 25$ $\mathrm{mmHg}$ at rest as assessed by right heart catheterization. Although right heart catheterization classically remains the gold standard for measurements of pulmonary artery systolic pressure (PASP), noninvasive Doppler quantification of tricuspid regurgitation peak velocity has emerged as a reliable and commonly employed tool to assess PASP at rest and with exercise. ${ }^{5}$ The true prevalence of $\mathrm{PH}$ in the general population is unknown, likely because of the broad classification and multiple etiologies. In the present study, $47 \%$ of patients above the age of 60 had a resting PASP of $>35 \mathrm{mmHg}$ where $35 \mathrm{mmHg}$ was adopted as the cut off value of normal RVSP. The prevalence dropped to $24 \%$ ( 47 patients) when $40 \mathrm{mmHg}$ was used as the cutoff point. This result is higher than the results reported by the following 3 studies. In Italy, they reported a prevalence of $8 \%$ in healthy volunteers aged $>50$ years and $6.8 \%$ of participants in an African-American population. ${ }^{6}$ A study in Armadale reported a prevalence of $9.1 \%{ }^{7}$

However, the estimate in this study may be inflated, as the study included participants referred for echocardiography, likely representing a population with increased risk as compared to the general population, and the case-definition method that used $35 \mathrm{mmHg}$ as a cut off value may have further inflated the estimate. Results of large registries showed that PAH was now more frequently diagnosed in elderly patients. Proportions of elderly patients with pulmonary hypertension were $63 \%$ (highest, COMPERA), 44\% (ASPIRE), $13.5 \%$ (UK, Ireland), 17\% (REVEAL), and 12.8\% (French), When it was considered the dates of these registries, the prevalence of elderly patients with $\mathrm{PH}$ was observed to be increasing over time and idiopathic PAH was most common type. However, these registries were not designed to evaluate exclusively elderly patients. ${ }^{8}$ Some studies assumed that PASP at rest increases with ageing reaching a value of 35 or $40 \mathrm{mmHg}$ at exercise. However, most of those studies were based on evaluation of healthy young volunteers no data are available concerning the cut-off value defining abnormal PASP in subjects of various age groups. ${ }^{9}$

The first published PAH registry described an affection that affects predominantly young women, with diagnosis occurring at a mean age of $<40$ years. ${ }^{10}$ In the present study, gender did not show any impact on the estimated pulmonary artery pressure among elderly patients. This finding is supported by recent registries on the elderly that stated that the modern picture of PAH is changing with patient registries showing an increase of the mean age at PAH diagnosis and an increase in the proportion of male patients. In one single-center registry, the mean age of idiopathic PAH diagnosis was $55 \pm 16$ years and, in the recently published data from the Swiss registry, the mean age at PAH diagnosis $>60$ years and $56 \%$ were female. ${ }^{11}$ In the present study, systemic hypertension was prevalent among the patients with a non -significant increase in patients with elevated RVSP. This supported by Redfeild et al. ${ }^{5}$ who demonstrated that age-related vascular stiffening contributes to isolated systemic systolic hypertension in the elderly. The pulmonary vascular bed could also be affected by this leading to pulmonary artery stiffening. ${ }^{13}$

In this work, $92 \%$ of patients had diastolic dysfunction and only $3 \%$ had severe dysfunction grade III. This is supported by Redfeild et al. ${ }^{14}$ who showed that the prevalence of subclinical mild diastolic dysfunction, detected using echocardiographic screening of the general population was one-third in 65-74 year old and more than half in those aged $>75$ years. The same study showed that severe diastolic dysfunction occurs in 3\% of this population. In this work, patients with abnormal RVSP had an increased percentage of grades II and III diastolic dysfunction as compared to those with normal RVSP. 
However, this increase didn't reach statistical significance. Using the multivariate analysis, there was no correlation between RVSP and diastolic dysfunction. This finding is supported by Kane et al. ${ }^{15}$ who stated that abnormalities of diastolic function on echo do not appear to underlie the age-related changes in PA systolic pressure seen. This may implicate intrinsic pulmonary arterial changes with age. Chen et al. ${ }^{16}$ noticed an age-related decrease in left heart compliance, which leads to progressive left ventricular diastolic dysfunction and PASP with exercise.

On the other hand, a recent community-based echocardiography study found a significant correlation between age-related increases in PA pressures with an age-dependent elevation in LV filling pressures. ${ }^{17}$ This discrepancy may be related to the different cohort of patients included in the present work from the community-based studies and the lack of comprehensive study of the LV diastolic function in the current work. In the present study, age showed a significant positive correlation with RVSP. This finding is supported by recent registries that showed progressive increase of PASP with increased age and related this to the effects of ageing on the respiratory system. They mentioned a progressive decline in lung function, which is associated with an alteration of the system mechanics of the lung-thorax and shows a decrease in static elastic recoil of the lung, an increase of chest-wall stiffness and a decrease in the respiratory muscles strength. All these factors may lead to or facilitate PVR increase and subsequent development of $\mathrm{PH}$ even in the absence of clear associated disease. ${ }^{18}$ Pulmonary hypertension in the elderly is not different than in other age group. However, the distinction between disease and normal ageing may be more difficult. In fact, the much comorbidity that could lead to pulmonary hypertension makes its diagnostic classification much more difficult and the identification of patients with a true vascular disease even more challenging. In addition, agerelated physiological changes should be considered if $\mathrm{PH}$ is suspected in the elderly because the normal process of ageing has the potential to lead to an over diagnosis of Pulmonary hypertension. ${ }^{19}$

\section{Conclusion}

Pulmonary artery systolic pressure was higher than the expected normal values $(35 \mathrm{mmHg}$ ) in $47 \%$ of patients above 60 years of age and this dropped to $24 \%$ when $40 \mathrm{mmHg}$ was used as the cutoff value for normal level.

Grade I diastolic dysfunction was prevalent among the study group and only $3 \%$ had severe form of dysfunction. There was no significant correlation with PASP.

No gender predilection of abnormal PASP in the aged population.

Systemic hypertension was prevalent among patients with abnormal PASP.

Pulmonary artery systolic pressure showed a significant direct correlation with age.

\section{Acknowledgments}

None.

\section{Conflicts of interest}

Author declares that there is no conflicts of interest.

\section{References}

1. Bossone E, D'Andrea A, Citro R, et al. Echocardiography in pulmonary arterial hypertension: an essential tool. Chest. 2007;131(2):339-341.

2. Douglas P, Khandheria B, Stainback R, et al. ACCF/ASE/ACEP/ASNC/ SCAI/SCCT/SCMR 2007 appropriateness criteria for transthoracic and transesophageal echocardiography: a report of the American College of Cardiology Foundation Quality Strategic Directions Committee Appropriateness CriteriaWorking Group, American Society of Echocardiography, American College of Emergency Physicians, American Society of Nuclear Cardiology, Society for Cardiovascular Angiography and Interventions, Society of Cardiovascular Computed Tomography, and the Society for Cardiovascular Magnetic Resonance endorsed by the American College of Chest Physicians and the Society of Critical Care Medicine. J Am Coll Cardiol. 2007;50:187-204.

3. Mahan G, Dabestani A, Gardin J, et al. Estimation of pulmonary artery pressure by pulsed Doppler echocardiography. Circulation. 1983;68:367-369.

4. Dabestani A, Mahan G, Gardin J, et al. Evaluation of pulmonary artery pressure and resistance by pulsed Doppler echocardiography. Am J Cardiol. 1987;59(6):662-668.

5. Majoub H, Levy F, Cassol M, et al. Effects of age on pulmonary artery systolic pressure at rest and during exercise in normal adults. European Journal of Echocardiography. 2009;10:635-640.

6. D'Andrea A, Naeije R, Grunig E, et al. Echocardiography of the Pulmonary Circulation and Right Ventricular Function: Exploring the Physiologic Spectrum in 1480 Normal Subjects. Chest. 2014;145(5):1071-1078.

7. Strange G, Playford D, Stewart S, et al. Pulmonary hypertension: prevalence and mortality in the Armadale echocardiography cohort. Heart. 2012;98(24):1805-1811.

8. Örem C. Epidemiology of pulmonary hypertension in the elderly. $J$ Geriatr Cardiol. 2017;14(1):11-16.

9. Bossone E, Rubenfire M, Bach D, et al. Range of tricuspid regurgitation velocity at rest and during exercise in normal adult men: implications for the diagnosis of pulmonary hypertension. $J$ Am Coll Cardiol. 1999;33:1662-1666.

10. Rich S, Dantzker D, Ayres S, et al. Primary PH. A national prospective study. Ann Intern Med. 1987;107:216-223.

11. Mueller-Mottet S, Stricker H, Domenighetti G, et al. Long-Term Data from the Swiss Pulmonary Hypertension Registry. Respiration. 2015;89:127-140.

12. Redfield M, Jacobsen S, Borlaug B, et al. Age- and gender-related ventricular-vascular stiffening: a community-based study. Circulation. 2005; 112:2254-2262.

13. Hosoda Y, Kawano K, Yamasawa F, et al. Age-dependent changes of collagen and elastin content in human aorta and pulmonary artery. Angiology. 1984;35(10):615-621.

14. Redfield M, Jacobsen S, Burnett J, et al. Burden of systolic and diastolic ventricular dysfunction in the community: appreciating the scope of the heart failure epidemic. JAMA. 2003;289:194-202.

15. Kane C, Arun Sachdev, Hector R, et al. Impact of age on pulmonary artery systolic pressures at rest and with exercise. Echo research and practice. 2016;3(2):53-61.

16. Chen C, Nakayama M, Nevo E, et al. Coupled systolic- ventricular and vascular stiffening with age: implications for pressure regulation and cardiac reserve in the elderly. J Am Coll Cardiol. 1998;32:1221-1227. 
17. Lam C, Borlaug B, Kane G et al. Age-associated increases in pulmonary artery systolic pressure in the general population. Circulation. 2009; 119(20):2663-2670

18. Janssens J, Pache J, Nicod L. Physiological changes in respiratory function associated with ageing. Eur Respir J. 1999;13:197-205.
19. Berra G, Noble S, Soccal P, et al. Pulmonary hypertension in the elderly: a different disease? Breathe. 2016;12(1):43-49. 